\title{
Snow in the Changing Sea-ice Systems
}

3 Melinda Webster ${ }^{1}$, Sebastian Gerland $^{2}$, Marika Holland ${ }^{3}$, Elizabeth Hunke ${ }^{4}$, Ron Kwok ${ }^{5}$, Olivier

4 Lecomte $^{6}$, Robert Massom $^{7}$, Don Perovich $^{8}$ and Matthew Sturm ${ }^{9}$

5

$6 \quad$ 11NASA Goddard Space Flight Center, 8800 Greenbelt Rd., Greenbelt, MD 20771, USA.

$7 \quad{ }^{2}$ Norwegian Polar Institute, Framsenteret, Hjalmar Johansens Gate 14, 9296 Troms $\emptyset$, Norway.

$8{ }^{3}$ National Center for Atmospheric Research, 1850 Table Mesa Dr., Boulder, CO 80305, USA.

$9 \quad{ }^{4}$ Los Alamos National Laboratory, Fluid Dynamics and Solid Mechanics Group T-3, Theoretical

10 Division, Los Alamos National Laboratory, MS-B216, Los Alamos, NM 87545, USA.

115 Jet Propulsion Laboratory, 4800 Oak Grove Dr., Pasadena, CA 91109, USA.

$12{ }^{6}$ Université Catholique de Louvain, Earth and Life Institute, Georges Lemaitre Centre for Earth

13 and Climate Research, Place Louis Paster 3, L4.03.08, 1348 Louvain-la-Neuve, Belgium.

$14 \quad{ }^{7}$ Australian Antarctic Division and Antarctic Climate and Ecosystems Cooperative Research

15 Centre, 20 Castray Esplanade, Hobart, Tasmania 7000, Australia.

$16{ }^{8}$ Thayer School of Engineering, Dartmouth College, 14 Engineering Dr., Hanover, NH 03755 ,

17 USA.

$18{ }^{9}$ University of Alaska Fairbanks, 505 South Chandalar Dr., Fairbanks, AK 99775, USA. 


\section{Abstract:}

As Earth's most reflective, insulative natural material, snow is critical to the sea-ice and climate systems, but its spatial and temporal heterogeneity poses challenges for observing, understanding and modelling those systems under anthropogenic warming. In this review, we survey the snowice system, then provide recommendations for overcoming present challenges. These include: (1) collecting process-oriented observations for model diagnostics and understanding snow-ice feedbacks, and (2) improving our remote sensing capabilities of snow for monitoring large-scale changes in snow on sea ice. These efforts could be achieved through stronger coordination between the observational, remote sensing and modelling communities, and would pay dividends through distinct improvements in predictions of polar environments

\section{$\underline{\text { 1. Introduction }}$}

Snow is the most reflective, and also the most insulative, natural material on Earth. Consequently, it is an integral component of Earth's climate. Snow regulates our planet's energy balance, reflecting $85 \%$ of incoming solar radiation back into space ${ }^{1-2}$. Without snow, the coupled atmosphere-land-ocean systems would gain energy through a positive feedback, and our planet would warm. As a whole, Earth's snow cover has decreased in duration and thickness under anthropogenic warming ${ }^{3-5}$, which has serious implications for the future trajectory of our climate.

37 Outside of the general trend, we do not know how 25\% of Earth's snow-covered regions is changing in a warming climate. This percentage represents the Arctic and Antarctic snow-sea ice systems, where snow plays a critical (and complex) role in the mass balance of sea ice and its response to a changing climate ${ }^{6-7}$. Snow enhances or curbs sea-ice loss depending on snow's thickness and properties, while sea-ice conditions, in turn, affect the snow (Fig. 1). Snow's 
42 physical, optical and thermal properties are heterogeneous in space and time due to snow's high 43 sensitivity to atmospheric and sea ice conditions, as well as its tendency to metamorphose over 44 time. Hence, snow processes widely differ in occurrence, magnitude and frequency between 45 seasons, regions and hemispheres.

46 Collectively, these and other factors (outlined below) greatly challenge our ability to 47 observe the current state of snow on sea ice, monitor long-term changes in snow conditions and 48 understand snow-related processes. These shortcomings limit our ability to realistically represent 49 the coupled snow-sea ice system in climate models and thus limit our prediction of long-term 50 changes and feedbacks in response to climate variability and change. Given the importance of 51 snow in the sea-ice and Earth systems, addressing these challenges is a high priority in climate 52 science, and, key to this perspective, these challenges may not be insurmountable. 

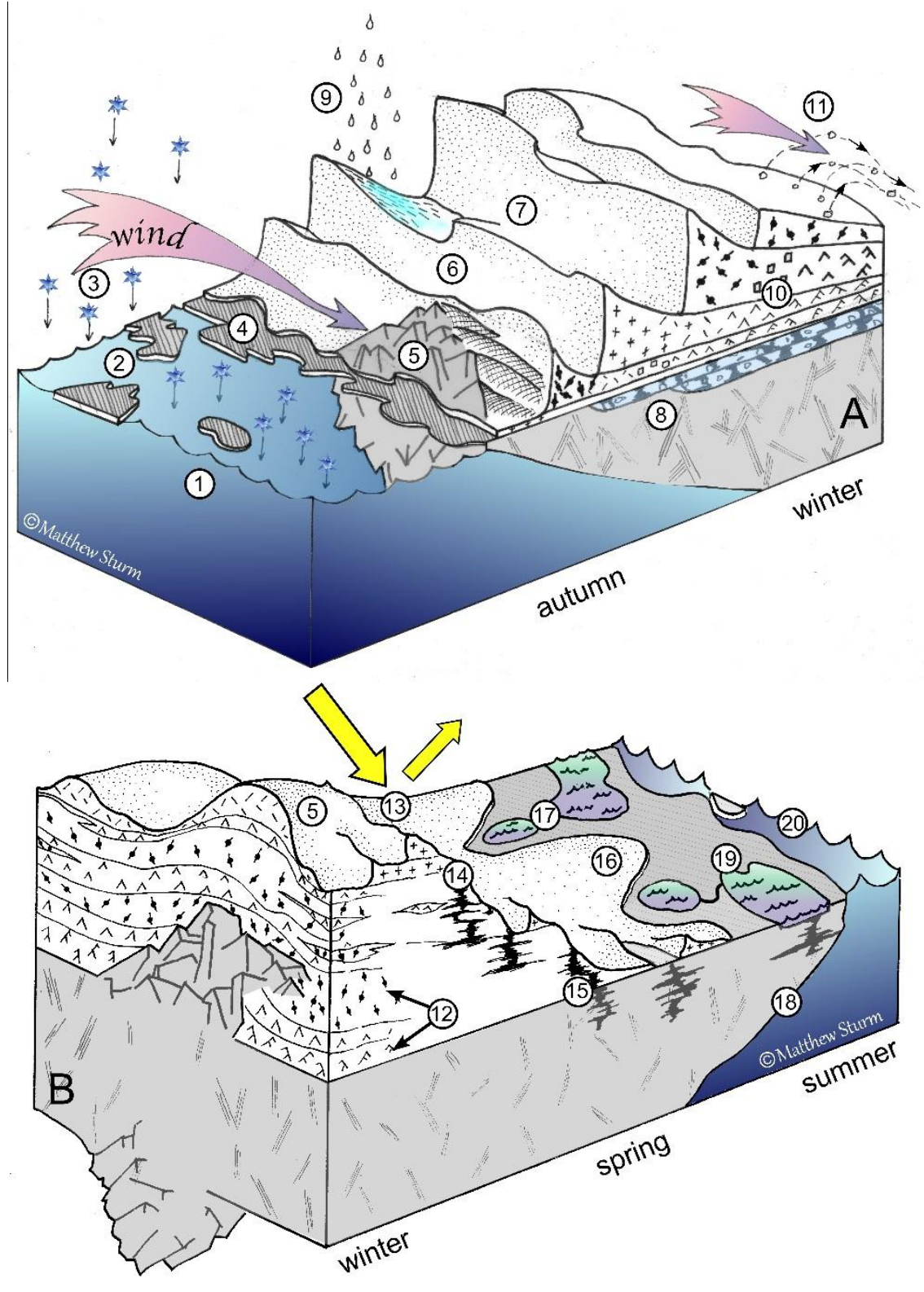

55 Figure 1/Box 1 Figure: An illustration conveying the complex set of processes that takes place

56 between snow and sea ice during (a) autumn-winter and (b) winter-summer. We exclude mid-

57 winter and mid-to-late summer from the illustration in order to highlight the dominant snow

58 processes. Box 1 contains the descriptions of the enumerated processes marked on the figure.

59 Note, certain processes are more dominant in one hemisphere than the other e.g., melt ponds in 60 the Arctic, snow-ice formation in the Antarctic (see Box 1 and ref 6). 


\section{Box 1: Generalized Sequence for Snow-on-Sea-Ice Processes}

\section{Autumn to Winter: Freeze-up and growth}

64 1. In autumn the sea surface cools,

65 2. to the extent that it begins to freeze, forming sea ice.

66 3. Snow may fall before the sea has frozen,

67 4. or a thin ice platform may intercept the snowfall, allowing it to accumulate.

68 5. Ice deformation driven by the wind and ocean currents creates surface roughness features

69 such as pressure ridges, which trap blowing snow to create deep drifts.

6. The uneven cover of insulating snow creates spatial gradients in heat loss, leading to

71 thermodynamic ice thickening that is heterogeneous.

72 7. Snow continues to deepen through a series of discrete snowfall events over the winter.

73 8. If thick enough, the snow overburden will exceed the buoyancy of the floe, resulting in ice-

74 surface flooding, often followed by freezing of the slush layer creating snow-ice $e^{8-10}$.

75 9. Occasionally, rain-on-snow events glaze the snow surface and "lock" snow in place.

76 10. Each layer of snow deposited goes through a complex metamorphic cycle that will alter its

77 grain size and density, and thus its physical, optical and thermal properties ${ }^{1,11-12}$,

78 11. Wind continues to erode or drift the snow, increasing heterogeneity of the snow cover ${ }^{13}$, and

79 blow snow particles into leads, where they may melt, form slush or nucleate freezing ${ }^{14}$.

81 Winter to Summer: Transition to melt

82 12. By late-winter a mature, heterogeneous snowpack covers the ice, keyed in some ways to the 83 deformation state of the ice and meteorological history. The snowpack composition includes two 
84 of the most dissimilar types of snow: depth hoar (porous, weak and highly insulative), and wind 85 slab (dense, hard and a relatively poor insulator $)^{13}$.

86 13. By spring, increasing temperatures and solar radiation will still start melting the snowpack 87 from the top down.

88 14. Meltwater then percolates downward through the snow to form internal ice layers and grain 89 coarsening that reduces the snow albedo ${ }^{1-2,12}$.

90 15. Where meltwater percolation reaches the snow-ice interface, it first forms superimposed

91 ice $e^{15-17}$, and eventually starts to collect as melt ponds (primarily in the Arctic). The snowmelt 92 may also percolate down into the ice via brine drainage channels and refreeze upon reaching 93 freezing-point temperatures, reducing the ice permeability and salinity ${ }^{18}$.

94 16. Where snow dunes have formed during the winter, the snow will last longer through the melt 95 season, and

96 17. the melt ponds will form adjacent to these dunes ${ }^{19-20}$ (in the Antarctic, austral summer melt is 97 generally insufficient to remove the snow cover on surviving ice floes, and melt ponds are rare ${ }^{10}$ ).

98 These freshwater features, together with the exposure of bare ice and the continued grain 99 coarsening, will reduce the surface albedo further ${ }^{2}$.

100 18. As seasonal melt progresses, the sea ice warms, which aids its basal melting by oceanic heat 101 fluxes.

102 19. With all of the snow gone, the (Arctic) melt ponds expand, link up and eventually drain, until 103 20. the sea ice either melts in place or breaks up. Some ice may survive the summer melt season. 104 In the Antarctic, greater snow survival in summer (and lack of melt ponds) may contribute to 105 survival of sea ice through the melt season, particularly at higher latitudes ${ }^{10}$.

\section{2. Snow in the sea-ice systems}


Across both the Arctic and Antarctic environments, snow on sea ice is governed by the

109

110

111

112

113

114

115

116

117

118

119

120

121

122

123

124

125

126

127

128

129

same set of physics. Strong vertical temperature gradients, for example, drive extensive snow grain metamorphism (Fig. 1A, 12), increasing the snow's insulating capacity ${ }^{21-22}$. Wind redistributes the snow to form a distinct "snowscape" shaped by and keyed to Arctic and Antarctic sea-ice topographies ${ }^{13,23-24}$ (Fig. 1A, 6). Open cracks, leads and polynyas within the sea ice cover act as a sink for snow during wind-driven redistribution ${ }^{14,25}$ (Fig. 1A, 11). In any region and at any time of year, ephemeral events such as rain-on-snow (Fig. 1A, 9) and thaw can affect the amount of snow removed and reworked by the wind ${ }^{26-28}$ and rapidly alter the snowpack's insulating and optical properties ${ }^{1,11-12}$.

Despite these same physics and snow-ice couplings, the unique geographical settings between the Arctic and Antarctic create marked deviations in the timing, magnitude and frequency of sea ice-atmosphere-ocean processes therein, which affects which snow processes dominate at any given time. These differences ultimately impact the mass balance of the Arctic and Antarctic sea ice covers and their responses to a changing climate. Thus, there are no "average climate properties of snow" that can be used in climate models to project the correct climate response - snow in the Arctic system will respond and contribute to climate change in a different way than the Antarctic system. Here, we provide a brief review of snow in the Arctic and Antarctic environments as a yardstick against which to assess long-term changes and highlight which processes require further scrutiny for better understanding and representation in Earth system models.

\subsection{Snow on Arctic sea ice}



formation, duration (e.g., ice age) and retreat, and the timing and magnitude of snowfall. The

132

133

134 significance of these controls is reflected in the distinct cross-basin gradient in snow depth distribution on Arctic sea ice ${ }^{29-32}$ (Fig. 2A). Climatologically speaking, the seasonal cycle in snow accumulation is comparable across all Arctic regions. In autumn, the snowpack grows rapidly due to frequent cyclone events ${ }^{29,33-34}$; however, for much of mid-winter, Arctic cyclone intensities decrease, resulting in relatively lower snowfall rates ${ }^{29,33-35}$ (Fig. 1A, 4). The seasonal tapering in snowfall differs regionally, with the Atlantic sector receiving the heaviest snowfall and rainfall year-round relative to other Arctic regions ${ }^{33,35}$. As a result, flooding and snow-ice formation occur in the Atlantic sector ${ }^{36-39}$ (Fig. 1A, 8), whereas elsewhere across the Arctic, snow-ice formation rarely occurs ${ }^{6}$ as snowfall rates are lower ${ }^{35}$ and the snowpack thinner and drier $^{28-29,38-39}$. The regional differences in coupled sea ice-snow-atmospheric processes lead to snow conditions that are appreciably unique $\mathrm{e}^{28-29,38-39}$, which warrants caution when looking for general changes in Arctic snow conditions, assessing model parameterizations and tuning remote sensing approaches based on a single or even multiple sets of in situ observations.

Over the last half century, a decrease in spring snow depth in the western Arctic has been observed from in situ, buoy and airborne data, and attributed to the delayed onset of sea-ice formation in autumn ${ }^{31}$ (Fig. 2B). Earlier work $^{29}$ found negative trends in snow depth for most months in 1954-1991, albeit insignificant with the exception of significant reductions in May (2 $\mathrm{cm} \mathrm{decade}^{-1}$ ). A thinning snow cover was also simulated in models of varying sophistication i.e., ranging from a fully coupled global climate model $^{40}$ to snow depth reconstructions from reanalysis snowfall ${ }^{41}$. Taken together, these results point to a clear and uni-directional response of the snow cover to Arctic sea ice loss: summer ice loss increases solar absorption and warming 
153 in the upper ocean ${ }^{42}$, which delays sea-ice formation in the subsequent autumn and reduces the

154 total amount of snow accumulation as more snow falls into open ocean than on sea ice (Fig. 1A,

155 3). Consequently, a thinner snow cover exposes sea ice to solar radiation earlier the following

156 spring, which contributes to the positive albedo feedback by decreasing the surface albedo during

157 a period of high insolation ${ }^{43}$ (Fig. 1B, 13-14). Increased solar absorption within the sea ice and

158 ocean enhances sea-ice loss and ocean warming ${ }^{42}$, to further delay sea-ice formation in the

159 subsequent autumn and reduce snow accumulation ${ }^{31,40}$.

160 In spring, Arctic melt onset has trended earlier in recent decades due to the combined

161 effect of higher air temperatures and larger moisture fluxes ${ }^{44-46}$. As melt progresses, the

162 distribution of snow influences the occurrence, location and timing of melt pond formation due

163 to its freshwater content ${ }^{16,18}$ and modification of the surface topography ${ }^{19-20}$ (Fig. 1B, 15-17). As

164 seasonal ice becomes increasingly common and melt onset earlier ${ }^{44-48}$, melt ponds will further

165 promote sea-ice loss due to their low albedo ${ }^{2,49-50}$ (Fig. 1B, 17).

166

167
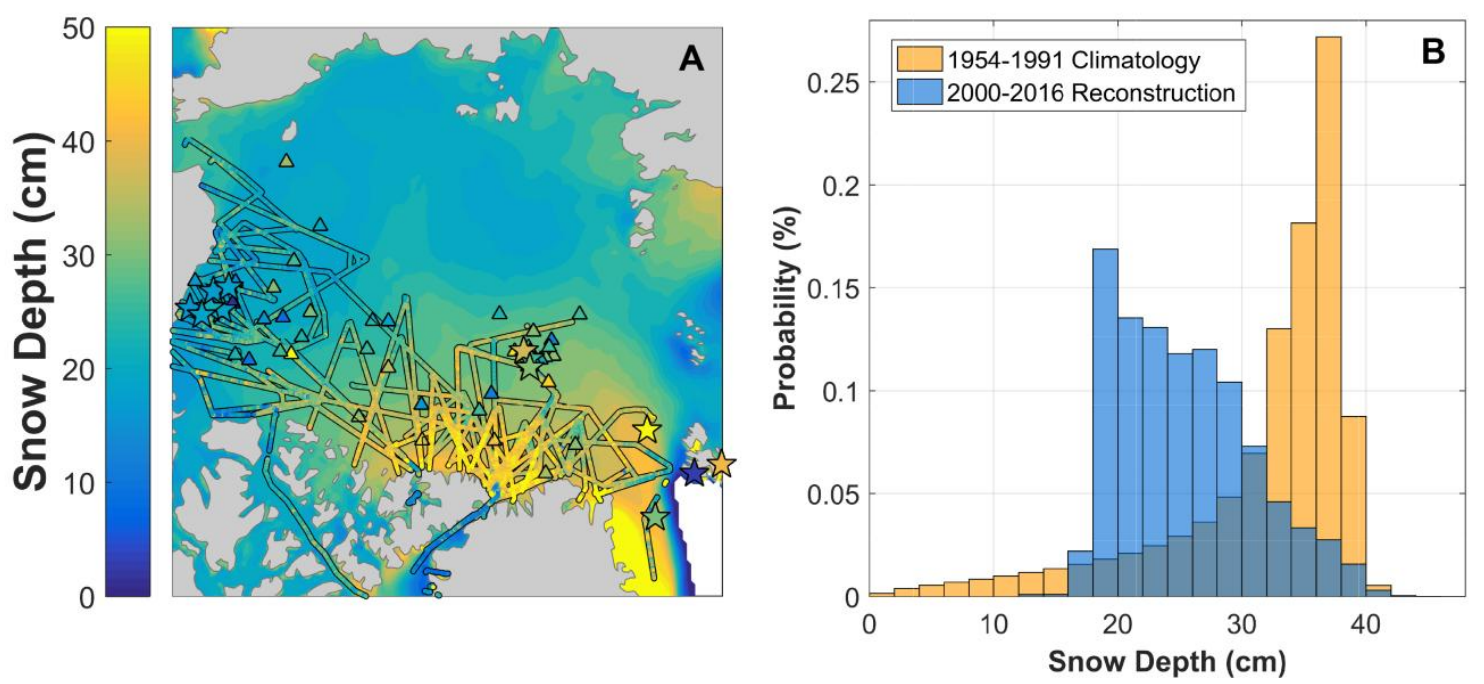

168 Figure 2. (A) Snow depth reconstruction for the Arctic Ocean in March-April for 2000-2016

169 from ERA-Interim reanalysis snowfall ${ }^{51}$. The reconstruction converts reanalysis snowfall to 
170 snow depth using the climatological snow density ${ }^{29}$ on sea-ice parcels that move with the wind 171 and ocean currents. Snow depth observations from different sources in 2000-2016 are overlaid as

172 symbols: Ice Mass Balance buoys ${ }^{52}$ from 2000-2016 are triangles; mean snow depths from field 173 campaigns are stars; and NASA Operation IceBridge 2009-2015 aerial surveys are basin-scale $174 \operatorname{lines}^{53}$. Note that the reconstruction excludes snow redistribution due to atmospheric processes 175 and ice dynamics, which may contribute to discrepancies with the observations. The Operation 176 IceBridge retrievals exclude snow-free (zero) values. (B) The snow depth distributions for 177 March-April from the 1954-1991 climatology ${ }^{29}$ and the 2000-2016 reconstruction showing a 178 marked reduction in depth. The bin size is $2 \mathrm{~cm}$. The reconstruction was chosen for comparison 179 due to the absence of observations in the spatial domain of the 1954-1991 climatology and the 180 good agreement between the reconstruction and observations ${ }^{54}$. A factor to consider when 181 interpreting the frequency distributions is that the spatial averaging differs between the 19541821991 climatology (e.g., 500-m and 1000-m averages) and 2000-2016 reconstruction (e.g., a 25$183 \mathrm{~km}$ gridded product). These differences in spatial averaging contribute to the differing shapes of 184 the distributions, with the 1954-1991 averages retaining more variability and thus yielding a 185 wider frequency distribution while the $25-\mathrm{km}$ gridded average reduces the spatial variability and 186 constrains the shape of the frequency distribution. The mean difference of $\sim 10 \mathrm{~cm}$ between the 187 1954-1991 climatology and 2000-2016 reconstruction is in agreement with findings from other 188 works $^{31,40-41}$.

2.2 Snow on Antarctic sea ice

While there are some similarities, the Antarctic snow-sea ice system differs from that of 192 the Arctic in several fundamental ways, underpinned by key differences in the geographical 
193 settings and the associated coupled sea ice-atmosphere-ocean interactions ${ }^{6,10,55}$. Antarctic sea ice 194 is mainly seasonal and exposed to the highly-dynamic circumpolar Southern Ocean. As such, the 195 Antarctic snow-sea ice system is very mobile ${ }^{10,56}$ and strongly influenced by frequent synoptic 196 events and strong winds ${ }^{27,57-58}$. Leads and polynyas are common features and, in general, 197 Antarctic sea ice is thinner than Arctic sea ice ${ }^{59-61}$. Another fundamental difference is the 198 absence of solar-absorbing melt ponds on Antarctic sea ice and the dominance of basal melt 199 during the relatively short melt season ${ }^{62}$. Accordingly, the surface albedo remains high 200 throughout the melt season due to the persistence of snow ${ }^{10,63}$.

201 Much like the Arctic ${ }^{64}$, snow depth distributions on Antarctic sea ice are strongly coupled 202 to the age of the ice and its surface roughness ${ }^{9}$. However, leads in the Antarctic may serve as a 203 more significant sink for wind-blown snow due to their greater prevalence and high frequency of 204 snowfall and wind events ${ }^{14,65}$. A recent study ${ }^{65}$ related very thick snow $(0.45-\mathrm{m}$ mean) to a lack 205 of leads in a region where, in previous years, open leads and a significantly thinner snowpack 206 were observed. This finding underlines the importance of sea-ice dynamics and strong winds in 207 determining the snow depth on Antarctic sea ice, as also demonstrated by recent modelling 208 study $^{66}$, and may shed insight into processes that may play an increasingly important role in the 209 Arctic snow-sea ice system in a changing climate.

210 In addition to being younger, thinner and more dynamic, the Antarctic snow-sea ice 211 system is also characterized by highly-variable meteorological conditions ${ }^{10}$ in which heavy 212 snowfall and synoptically-driven thaw events occur year-round ${ }^{27,67}$. The combined effect of 213 heavy snowfall and thinner ice results in widespread flooding and snow-ice formation (Fig. 1A, 214 8), with the latter serving as an important positive mass contribution to Antarctic sea ice ${ }^{9,26,68-69}$. 215 Although short-lived, thaw and rainfall events significantly alter the snowpack's thermal and 
216 optical properties, and can form ice layers and crusts ${ }^{9}$ which "lock in" the snow, preventing

217 drifting ${ }^{15,26-28}$ (Fig. 1A, 9). The upward wicking of brine from the sea-ice surface typically

218 creates a damp, saline layer at the base of the snowpack, even in the absence of flooding ${ }^{27-28,69-70}$.

219 An important consequence of wet snow, in addition to increasing its thermal conductivity, is a

220 decrease in albedo, with this effect remaining after the wet snow refreezes ${ }^{1,11,63}$.

221 Regarding the data record, Antarctic snow observations are even sparser than the Arctic's.

222 This is due to the extreme remoteness and harshness of the Southern Ocean and the greater

223 difficulty in accurately deriving snow characteristics from remote sensing data ${ }^{71}$ owing to the

224 more structurally-complex nature of the Antarctic snowpack (e.g., extensively flooded, more

225 strongly layered, often saline and damp $)^{10,15,28}$. Given these limitations, there is currently no

226 climatological baseline against which to i) identify long-term changes in snow conditions on

227 Antarctic sea ice, or ii) gain fuller understanding of the Antarctic snow-sea ice system evolution

228 over an annual cycle. Nevertheless, existing observations have revealed key differences in

229 processes and conditions that distinguish the Antarctic snow-sea ice system from the Arctic.

230 These differences include: (1) more snow-ice formation, (2) more snow lost to leads, (3) more

231 thaw and (4) more rain-on-snow events. Although some Earth system models include some of

232 these processes (e.g., the Community Earth System Model), we propose that accounting for these

233 processes in climate modelling will be a major step towards more accurately projecting the future

234 of the Antarctic system in a changing climate. 

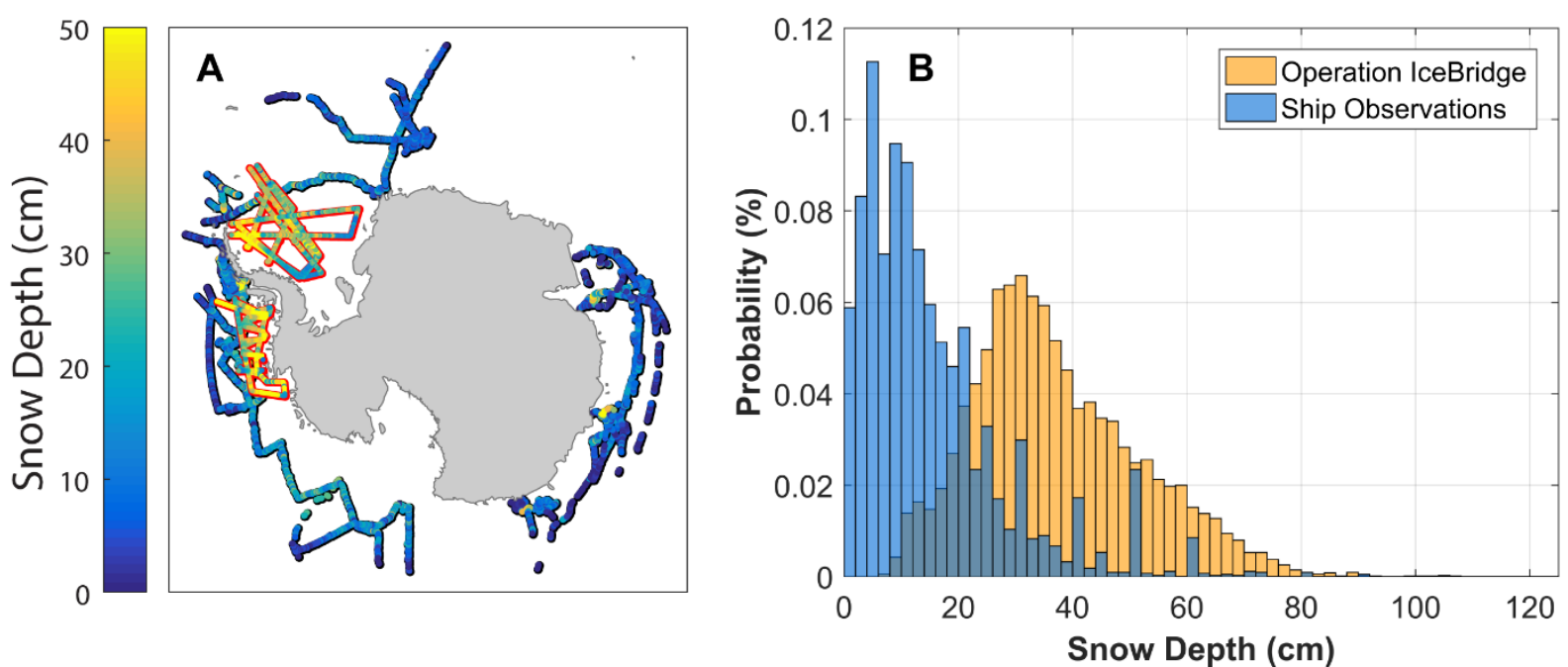

236

237

238

239

240

241

242

243

244

245

246

247

248

249

250

251

Figure 3. (A) September-November (austral spring) snow depth distributions on Antarctic sea ice based on ship observations (black outline) compiled by ref. 59 and derived from Operation IceBridge snow radar data (red outline $)^{72}$. Note that the deeper snow depth retrievals from Operation IceBridge flights may result from greater sampling of thicker, more deformed ice later in the season relative to the ship observations. (B) The snow depth distributions for SeptemberNovember from ship observations and Operation IceBridge. The histogram excludes snow-free values from the ship observations (making up $\sim 10 \%$ of the total) for an objective comparison with the airborne data, which excludes snow-free values. The bin size is $2 \mathrm{~cm}$.

\section{Key challenges and knowledge gaps}

To improve predictions of polar climate change and its effects, we need to represent the Arctic and Antarctic snow-sea ice systems accurately. For that, two things need to happen, both challenging. First, we need to know which aspects of the complex processes shown in Figure 1 need to be represented in the models (or the projections will be wrong). Second, we need to be able to obtain much-improved observations of snow processes and spatial fields of snow depth 
252 and properties against which model results can be compared and models subsequently improved.

253 As noted earlier, considerable physical and logistical challenges limit the collection of snow 254 observations at the spatial and temporal frequencies required for monitoring and understanding 255 changes in snow conditions. Not only this, remote sensing of snow on sea ice remains a 256 challenge given the complexity of the snow substrate and the heterogeneity of the underlying sea

257 ice as both affect the electromagnetic signature ${ }^{71}$. However, these challenges may be 258 surmountable.

\subsection{Model treatment of snow on sea ice}

Although climate models have inherent biases and uncertainties ${ }^{73}$, they are the only means for understanding and predicting snow conditions on sea ice and their feedbacks at scales relevant to climate and climate change. To date, the treatment of the snow-sea ice system has been relatively simplistic in climate models ${ }^{74}$ compared with treatments for snow on land. The micro-scale physics that define the macroscopic thermo-optical properties of snow on sea ice are relatively well-known and certain key relationships have been proposed (e.g., between effective snow thermal conductivity and bulk snow density ${ }^{75}$ ). However, it is unclear whether the incorporation of such relationships/processes reduce or increase current uncertainties in climate models - given the sparsity of input data, the lack of space- and time-independent observations applicable to different climate scenarios and the issue of reasonably representing small-scale

271 processes at the aggregate-scale. For example, the treatment of different phases (vapor, liquid, 272 solid) in the snowpack and their interactions with other physical processes have not been 273 addressed in sea-ice models, and one can only speculate about the effective impacts of such 274 higher-order mechanisms on large-scale climate simulations. Previous works have demonstrated 
275 the large sensitivity of sea-ice and climate simulations to thermo-physical parameters ${ }^{76-78}$. To 276 date, however, none have clearly disentangled primary from secondary processes regarding their

277 relative importance in simulating realistic behavior of the snow-sea ice system under changing 278 climate. This is in large part due to the absence of process-oriented diagnostics from 279 observations.

280 Ensuring a high-fidelity simulation of snow on sea ice requires: (1) reasonable 281 precipitation forcing, (2) reasonable representation of factors driving snow loss and melt and (3) 282 model evaluation methods to both assess snow in present climate simulations and pinpoint 283 critical processes defining the snowpack in transient climate experiments. Both model- and 284 observation-based precipitation data for (1) suffer from large uncertainties culminating from the 285 lack of precipitation observations at high latitudes, biases associated with precipitation gauges ${ }^{79}$, 286 the varying sophistication of parameterized cloud physics and inherent model biases ${ }^{80}$. For (2), 287 we face challenges in modelling snow melt due to the complexity of observing and simulating 288 time-varying changes in atmospheric forcing, surface conditions and albedo. Additionally, snow "loss" due to wind-blown redistribution and snow-to-sea ice conversion (from flooding at the snow-ice interface) can lead to potential discrepancies between modeled (and observed) snowfall 291 and actual snow accumulation on sea ice ${ }^{69}$. The two distinct types of model evaluation in (3) are 292 constrained by the differing scales between in situ snow observations and climate model 293 resolutions and the significant uncertainties in remote sensing observations ${ }^{71,81-82}$.

294 Improving the coverage and quality of large-scale snow observations is a way forward for 295 designing standard error metrics to evaluate the key snow state variables (depth, albedo, density) 296 in current climate conditions. Equally important are process-oriented metrics for exposing 297 inaccurate or missing mechanisms that drive the evolution of snow conditions in climate models. 
298 Process-oriented metrics also allow assessment of snow's contribution in feedbacks with other

299 climate system elements, which is essential for understanding snow's role in various climate

300 regimes. Although such diagnostics have recently been developed for sea-ice processes and polar

301 feedbacks ${ }^{83-84}$, much work remains to be done regarding snow itself. Such efforts will be a leap

302 forward in our understanding of snow's role in the climate system when coincident atmosphere-

303 ice-ocean observations appropriate for quantifying processes and feedbacks become available.

304 Snow-on-sea ice modelling can also benefit from advances made by the terrestrial snow

305 modelling community, which has developed more comprehensive snow models ${ }^{85}$. The fact that

306 snow lies on a moving, deforming sea-ice platform to which it is closely coupled remains a

307 considerable challenge. However, some snow processes are transferable to sea-ice frameworks,

308 as recently done for wind-driven snow redistribution on level ice ${ }^{86}$. Testing such complex snow

309 schemes (from terrestrial snow models) on sea ice could provide valuable insight to determine

310 the scales at which specific snow processes might become irrelevant for climate models.

311

$312 \quad 3.2$ Improving observations of snow on sea ice

313 Ideally, we would have recurring, consistent and scalable observations that capture the

314 seasonal evolution of snow depth, density and albedo across both polar sea-ice covers. However,

315 there are no current observing systems in place or planned future systems to routinely generate

316 large-scale maps of snow properties on sea ice, despite snow's significance to sea-ice mass

317 balance and thickness retrievals ${ }^{87}$. More so, existing in situ and remote sensing observations of

318 snow are severely limited in space, quality and time due to the spatial and temporal heterogeneity

319 of snow, substantial year-to-year variability, the vast scales involved and difficulties in accessing

320 extremely remote environments. Unique uncertainties are also associated with the type of 
321 observational method used, giving rise to caveats specific to data interpretation. Here, we discuss

322 the current limitations in observing snow on sea ice and introduce priorities for extending our 323 observational capabilities.

324 Snow depth distribution is one of the critical knowledge gaps of snow on sea ice due to 325 physical and instrumental constraints and our limited understanding of the mechanisms 326 governing snow accumulation and redistribution ${ }^{6,14}$. Remote sensing has a key role to play in 327 addressing this issue, yet key challenges remain. On regional scales, airborne and satellite 328 systems reach instrumental constraints due to range resolution issues, creating a lower-bound to 329 snow depth retrievals based on the ability to separate the air-snow and snow-ice interfaces e.g., $330 \sim 5-8 \mathrm{~cm}$ minimum for the Operation IceBridge snow radar ${ }^{53,72,88}$. Over deformed sea ice, an ice 331 type typically under-sampled in field observations, radar returns are scattered in several 332 directions, resulting in a rather indistinct air-snow interface. In these cases, the data are often 333 discarded ${ }^{53,89}$. In regions with saline snow, radar-derived snow depths may be biased low due to 334 an erroneous detection of a shallow, saline interface ${ }^{82}$. Relative to radar, satellite passive microwave retrievals of snow depth provide substantial coverage of the polar sea ice covers on a 336 daily basis at $25-\mathrm{km}$ spatial resolution ${ }^{90-91}$, but they too have inadequacies. Passive microwave 337 snow depth retrievals are limited to areas of first-year sea ice outside the marginal ice zone and 338 to snow depths of $50 \mathrm{~cm}$ and less, and underestimate snow depth by a factor of 2 to 3 over rough 339 surfaces $^{92-94}$.

340 Collectively, these remote sensing limitations may contribute to a poor characterization 341 of snow specific to different ice types and their corresponding contribution to the overall snow 342 depth distribution. These findings highly motivate focused efforts towards quantifying and 343 constraining uncertainties and biases associated with remotely sensed snow properties over all 
344 ice types. This can be achieved through strategic coordination between field, airborne and

345 satellite campaigns targeting wide-ranging snow and sea ice conditions to collect coincident,

346 scalable data that are more representative of the heterogeneous snow-sea ice systems.

347 Constraining uncertainties is also aided by technological advancements and improved

348 instrumentation (e.g., finer radar range resolution) for more accurate detection of air-snow-ice

349 interfaces.

350 Another major challenge to measuring snow is that it is governed by time-variant

351 processes that operate at different spatial scales ${ }^{6}$. The pack ice zone continually transforms with

352 ice dynamic and snow thermodynamic processes. Accordingly, the time-space evolution of the

353 snow heterogeneity in both depth and properties is complex (Fig. 1). There is a critical need for

354 quantifying the mechanisms driving snow heterogeneity and how their magnitude of influence

355 evolves seasonally. Key processes requiring further scrutiny include snow lost to leads ${ }^{14}$ and via

356 snow-ice formation ${ }^{9-10}$ and the impact of melt ${ }^{44,46,67}$ and rain-on-snow events as a function of

357 season and region ${ }^{95}$. To make progress on these priorities, collecting data specific to atmosphere-

358 snow-sea ice interactions is essential, such as time-series of coincident meteorological (wind

359 speed, air temperature, humidity, precipitation amount and phase), sea ice (orientation of 360 topographic features and leads) and snowpack conditions (porosity, snow grain size and shape,

361 the presence of liquid within the snowpack). Models can help reveal which processes may

362 dominate in specific regions, which can be further guide field experiments for documenting,

363 testing and better understanding these processes so that they can be readily linked with model

364 diagnostics and development.

365

366 4. Future steps 

needs and improving our understanding of, and ability to predict, snow on Arctic and Antarctic sea ice. These approaches are achievable through the synthesis of observational, remote sensing and modelling efforts, as shown by examples below.

\section{4.1 Basin-scale sampling (remote sensing)}

373 There are currently no observational systems in place dedicated to basin-scale mapping of snow on sea ice. However, there are two potential opportunities to measure and monitor snow at basin-

375 scale: (1) mapping with autonomous aircraft (e.g., Global Hawk), which requires less support than traditional airborne missions (e.g., Operation IceBridge), and (2) multi-sensor approaches and the merging of different satellite products ${ }^{87,96-97}$. One such avenue of the latter is the synthesis of ICESat-2 laser and CryoSat-2 radar altimeter data, which depends on their operational success, the availability of sufficient crossovers of their orbital swaths in space and time and retrieval uncertainties. Theoretically, ICESat-2 and CryoSat-2 will detect the distance to the air-snow and snow-ice interfaces, respectively. The difference will yield snow depth. This concept has been successfully demonstrated using airborne and satellite data, and shows promise

383 as a future source of snow depth retrievals on sea ice at basin-scale ${ }^{97}$. Before opportunities like this are pursued, however, it is essential to cross-communicate the differing needs (e.g., accuracy, spatial and temporal resolutions) of the modelling and remote sensing communities to ensure that the resulting uncertainties are sufficiently low to be useful. For example, a snow depth product gridded at $25-\mathrm{km}$ resolution with a $5-\mathrm{cm}$ uncertainty addresses the needs of the remote sensing community for accurate sea ice thickness retrievals as well as those by the modelling community as a standard error metric, and is a realistic goal within the coming decades. Algorithm 
390

391

392

393

394

395

396

397

398

399

400

401

402

403

404

405

406

407

408

409

410 411 conditions ${ }^{55}$. Standardized autonomous systems should be strategically deployed in networks and 412 from all ships traversing the polar sea ice zones e.g., coordinated within the Southern Ocean

development, calibration and validation using suitable surface and airborne datasets are vital to the success of such efforts. Implementing multi-regional arrays of coordinated field, airborne and satellite programs provide the means for gaining a deeper understanding of uncertainty sources over variable surface conditions and subsequently improving our remote sensing capabilities of snow on sea ice.

\subsection{Targeting opportunities}

As underscored throughout this review, process-oriented observations are critical for better understanding snow on sea ice and its feedbacks in the climate system. These observations can also inform parameterization development in models, ultimately leading to more robust predictive capability. Therefore, time-series of process-relevant data should be collected at every opportunity and at the necessary quantities for applying the same process-oriented diagnostics as those in models. To maximize the value of such observations, it is essential to maintain a continual dialogue between the modelling and observational communities ${ }^{98}$ and, of equal importance, carry out model-observation cross-community coordination in future campaigns and missions (e.g., http://www.mosaicobservatory.org/).

Over the last decade, autonomous observing systems (e.g., ice mass balance buoys ${ }^{52,99}$, snow buoys ${ }^{100}$, webcams, automated weather systems) have advanced our ability to collect a large breadth and frequency of snow and associated sea ice and meteorological data ${ }^{55}$. These serve as ideal platforms for adding to our understanding of snow-sea ice processes and the evolution of snow properties as they relate to precipitation, air temperature and wind and sea-ice 
413 Observing System SOOS: www.soos.aw. Such coordination will facilitate their combination 414 with complementary instrument packages, field campaigns, aircraft overflights and satellite 415 passes. These combined datasets yield considerable insight into the mechanisms influencing 416 changes in the coupled snow-sea ice-atmosphere-ocean system, as well as their seasonal, inter417 annual and regional evolution. The collection of snow, sea ice and meteorological data can also 418 be expanded by non-scientists traveling to the Arctic and Antarctic sea-ice environments ${ }^{30}$. 419 Standardized sampling protocols have been developed and successfully implemented for 420 cataloguing sea-ice conditions via research cruises (e.g., 421 https://sites.google.com/a/alaska.edu/ice-watch/), and can be readily enhanced and made 422 accessible for non-scientists given the increase in tourism at high latitudes.

\subsection{Conclusion} snow on sea ice is a complex medium strongly coupled to atmospheric, oceanic and sea 426 ice conditions and thus heterogeneous in space and time (Fig. 1). This inherent nature of snow 427 poses important challenges in collecting observations suitable for assessing and developing sea428 ice and climate models. We have provided context and strong motivation for coordinating efforts to obtain process-oriented observations as diagnostics for sea-ice and global climate models and to improve our remote sensing capabilities of snow on sea ice. Through considered synthesis of observational, remote sensing and modelling efforts, we can attain a more complete picture of

432 how Earth's snow-covered regions are changing under anthropogenic warming and gain a richer 433 understanding of snow's role in the global sea-ice and climate systems. These coordinated efforts 434 will leap forward our ability to predict the future role of snow in modulating the response of sea 435 ice, and Earth, to a changing climate. 
437 Acknowledgements:

438 M. Sturm was funded by the NASA Terrestrial Hydrology Program. R. Massom was supported 439 by the Australian Antarctic Division and the Australian Government's Cooperative Research 440 Centres Programme through the Antarctic Climate and Ecosystems Cooperative Research Centre. 441 D. Perovich and M. Webster were funded by the NASA Cryospheric Sciences Program. O. 442 Lecomte was supported by the Belgian Fonds National de la Recherche Scientifique (F.R.S.443 FNRS), and the European Commission's Horizon 2020 projects APPLICATE (GA 727862) and 444 PRIMAVERA (GA 641727). S. Gerland was supported by the project ID Arctic, funded by the 445 Norwegian Ministries for Foreign Affairs and Climate and Environment (program Arktis 2030). 446 We kindly thank the following for spring snow depth data shown in Figure 2A: C. Polashenski, 447 N. Wright, G. Liston, and C. Planck from the project Snow, Wind, and Time: Understanding 448 Snow Redistribution and its Effects on Sea Ice Mass Balance (Award Number: 1603361); B. 449 Notenboom on behalf of the 2-Degree North Pole Expedition; and the Norwegian Young Sea Ice 450 Cruise (N-ICE2015); B. Ousland (and T. Ulrich in 2007) from Arctic traverses in 2001 and 2007, 451 and A. Hubert and D. Dansercoer during the ESA-sponsored Arctic Arc expedition in 2007. 452 Lastly, we extend our gratitude to the senior editor and three anonymous reviewers for their time 453 in carefully reviewing the manuscript and providing helpful feedback.

454

455 Conflicting Interests

456 The authors declare no conflicting interests

457

458 Author contributions 
460

461

462

463

464

465

466

467

468

469

470

471

472

473

474

475

476

477

478

479

480

481

\section{References}

1. Warren, S. G. Optical-properties of snow. Rev. Geophys. 20(1), 67-89 (1982).

2. Perovich, D. K., Grenfell, T. C., Light, B. \& Hobbs. P. V. Seasonal evolution of the albedo of multiyear Arctic sea ice. J. Geophys. Res. 107(C10), 8044 (2002).

3. Derksen, C. \& Brown, R. Spring snow cover extent reductions in the 2008-2012 period exceeding climate model projections. Geophys. Res. Lett. 39, L19504 (2012).

4. IPCC, 2014: Climate Change 2014: Synthesis Report. Contribution of Working Groups I, II and III to the Fifth Assessment Report of the Intergovernmental Panel on Climate Change [Core Writing Team, R.K. Pachauri and L.A. Meyer (eds.)]. IPCC, Geneva, Switzerland, 151 (2014).

5. Mudryk, L. R., Kushner, P. J., Derksen, C. \& Thackeray, C. Snow cover response to temperature in observational and climate model ensembles. Geophys. Res. Lett. 44, 919-926 (2017).

6. Sturm, M. \& Massom, R. A. Snow in the sea ice system: Friend or foe, in Sea Ice, 3rd ed., 65-109 (ed. D. N. Thomas) (Wiley and Blackwell Ltd., Oxford, U. K., 2017).

7. Ledley, T. S. Snow on sea ice: competing effects in shaping climate. J. Geophys. Res. 96, $17195-17208$ (1991).

8. Maksym, T. \& Jeffries, M. O. A one- dimensional percolation model of flooding and snow ice formation on Antarctic sea ice. J. Geophys. Res. 105(26), 313-26, 332 (2000).

9. Jeffries, M. O., Krouse, H. R., Hurst- Cushing, B. \& Maksym, T. Snow- ice accretion and snow- cover depletion on Antarctic first- year sea- ice floes. Ann. Glaciol. 33, 51-60 (2001).

10. Massom, R. A. et al. Snow on Antarctic sea ice. Rev. Geophys. 39, 413-445 (2001). 
482 11. O'Brien, H. W., \& Munis, R. H. Red and near-infrared spectral reflectance of snow, CRREL

483 Res. Rep., 332, U.S. Army Cold Reg. Res. and Eng. Lab., Hanover, N.H., (1975).

484 12. Colbeck, S. C. The layered character of snow covers. Rev. Geophys. 291, 81-96 (1991).

485 13. Sturm, M., Holmgren, J. \& Perovich, D. K. Winter snow cover on the sea ice of the Arctic

486 Ocean at the Surface Heat Budget of the Arctic Ocean (SHEBA): Temporal evolution and 487 spatial variability. J. Geophys. Res. 107(C10), 8047 (2002).

488 14. Leonard, K. \& Maksym, T. The importance of wind-blown snow redistribution to 489 accumulation on and mass balance of Bellingshausen Sea ice. Ann. Glacio. 52(57), 271-278 $490 \quad$ (2011).

15. Haas, C., Thomas, D. N. \& Bareiss, J. Surface properties and processes of perennial 492 Antarctic sea ice in summer. J. Glaciol. 47, 613-625 (2001).

16. Eicken, H., Grenfell, T. C., Perovich, D. K., Richter-Menge, J. A. \& Frey, K. Hydraulic controls of summer Arctic pack ice albedo. J. Geophys. Res. 109, C08007 (2004).

17. Wang, C., Cheng, B., Wang, K., Gerland, S. \& Pavlova, O. Modelling snow ice and superimposed ice on landfast sea ice in Kongsfjorden, Svalbard, Polar Research, 34:1, 20828 (2015).

18. Polashenski, C. et al. Percolation blockage: A process that enables melt pond formation on first year Arctic sea ice. J. Geophys. Res. Oceans 122, 413-440 (2017).

19. Petrich, C. et al. Snow dunes: A controlling factor of melt pond distribution on Arctic sea ice. J. Geophys. Res. 117, C09029 (2012).

502

20. Polashenski, C., Perovich, D. K. \& Courville, Z. The mechanisms of sea ice melt pond 503 formation and evolution. J. Geophys. Res. 117, C01001 (2012). 
504 21. Maykut, G. A. \& Untersteiner, N. Some results from a time-dependent thermodynamic 505 model of sea ice. J. Geophys. Res. 76(6), 1550-1575 (1971).

506 22. Sturm, M., Perovich, D. K. \& Holmgren, J. Thermal conductivity and heat transfer through 507 the snow on the ice of the Beaufort Sea. J. Geophys. Res. 107(C21), 8043 (2002).

508 23. Filhol, S. \& Sturm, M. Snow bedforms: a review, new data and a formation model. $J$. 509 Geophys. Res. 120(9), 1645-1669 (2015).

510 24. Trujillo, E., Leonard, K., Maksym, T. \& Lehning. M. Changes in snow distribution and 511 surface topography following a snowstorm on Antarctic sea ice. J. Geophys. Res. Earth Surf. $512 \quad \mathbf{1 2 1}, 2172-2191(2016)$.

513 25. Déry, S. J. \& Tremblay, L.-B. Modeling the effects of wind redistribution on the snow mass 514 budget of polar sea ice. J. Phys. Oceanogr. 34, 258-271 (2004).

515 26. Eicken, H., Lange, M. A., Hubberten, H.-W. \& Wadhams, P. Characteristics and distribution 516 patterns of snow and meteoric ice in the Weddell Sea and their contribution to the mass 517 balance of sea ice. Ann Geophys. 12, 80—93 (1994).

518 27. Massom, R. A., Drinkwater, M. R. \& Haas, C. Winter snow cover on sea ice in the Weddell 519 Sea. J. Geophys. Res. 102, 1101-1117 (1997).

520 28. Sturm, M., Morris, K. \& Massom, R. The winter snow cover of the West Antarctic pack ice: 521 Its spatial and temporal variability, Antarctic Sea Ice Physical Processes, Interactions and 522 Variability, Antarct. Res. Ser. 74, 19-40 (ed. M. O. Jeffries) (AGU, Washington, D. C., 523 1998).

524 29. Warren, S. et al. Snow depth on Arctic sea ice. J. Clim. 12, 1814-1829 (1999).

525 30. Gerland, S. \& Haas, C. Snow-depth observations by adventurers traveling on Arctic sea ice. 526 Ann. Glaciol. 52(57), 369-376 (2011). 
527 31. Webster, M. A. et al. Interdecadal changes in snow depth on Arctic sea ice. J. Geophys. Res.

$528 \quad$ Oceans 119, 5395-5406 (2014).

529 32. Haas, C. et al. Ice and snow depth variability and change in the high Arctic Ocean observed 530 by in situ measurements. Geophys. Res. Lett. 44, 10462-10469 (2017).

531 33. Simmonds, I., Burke, C. \& Keay, K. Arctic climate change as manifest in cyclone behavior. $J$. 532 Clim. 21, 5777-5796 (2008).

533 34. Lique, C., Holland, M. M., Dibike, Y. B., Lawrence, D. M. \& Screen, J. A. Modeling the 534 Arctic freshwater system and its integration in the global system: lessons learned and future 535 challenges. J. Geophys. Res. Biogeosciences 121, 540-566 (2016).

536 35. Boisvert, L. et al. Intercomparison of precipitation estimates over the Arctic Ocean and its 537 peripheral seas from reanalyses. J. Clim. (in review).

538 36. Granskog, M. A. et al. Snow contribution to first-year and second-year Arctic sea ice mass 539 balance north of Svalbard. J. Geophys. Res. Oceans 122, 2539-2549 (2017).

540 37. Provost, C., et al. Observations of flooding and snow-ice formation in a thinner Arctic sea-ice 541 regime during the N-ICE2015 campaign: Influence of basal ice melt and storms. J. Geophys. $542 \quad$ Res. Oceans 122, 7115-7134 (2017).

543 38. Merkouriadi, I., Cheng, B., Graham, R. M., Rösel, A., \& Granskog, M. A. Critical role of 544 snow on sea ice growth in the Atlantic sector of the Arctic Ocean. Geophys. Res. Lett. 44, 10, $545 \quad 479-10,485$ (2017).

546 39. Gallet, J.C., et al. Spring snow conditions on Arctic sea ice north of Svalbard during the 547 Norwegian young sea ICE (N-ICE2015) expedition. J. Geophys. Res. Atmos. 122 (2017). 
40. Hezel, P. J., Zhang, X., Bitz, C. M., Kelly, B. P. \& Massonnet, F. Projected decline in spring snow depth on Arctic sea ice caused by progressively later autumn open ocean freeze-up this century. Geophys. Res. Lett. 39, L17505 (2012).

41. Blanchard-Wrigglesworth, E., Webster, M. A., Farrell, S. L. \& Bitz, C. M. Reconstruction of snow on Arctic sea ice. J. Geophys. Res. Oceans (2018).

42. Perovich, D. K. et al. Increasing solar heating of the Arctic Ocean and adjacent seas, 19792005: Attribution and role in the ice-albedo feedback. Geophys. Res. Lett. 34, L19505 (2007).

43. Holland, M. M. \& Landrum, L. Factors affecting projected Arctic surface shortwave heating and albedo change in coupled climate models. Philos. Trans. Roy. Soc. London, 373A, $20140162(2015)$.

44. Markus, T., Stroeve, J. C. \& Miller, J. Recent changes in Arctic sea ice melt onset, freezeup, and melt season length. J. Geophys. Res. 114, C12024 (2009).

45. Stroeve, J. C., Markus, T., Boisvert, L., Miller, J. \& Barrett, A. Changes in Arctic melt season and implications for sea ice loss. Geophys. Res. Lett. 41, 1216-1225 (2014).

46. Bliss, A. C., Miller, J. A. \& Meier, W. N. Comparison of passive microwave-derived early melt onset records on Arctic sea ice. Remote Sens. 9, 199 (2017).

47. Nghiem, S. V. et al. Rapid reduction of Arctic perennial sea ice. Geophys. Res. Lett. 34, L19504 (2007).

48. Maslanik, J., Stroeve, J., Fowler, C. \& Emery, W. Distribution and trends in Arctic sea ice age through spring 2011. Geophys. Res. Lett. 38, L13502 (2011).

49. Nicolaus, M., Katlein, C., Maslanik, J. \& Hendricks, S. Changes in Arctic sea ice result in increasing light transmittance and absorption. Geophys. Res. Lett. 39, L24501 (2012). 
570

571

572

573

574

575

576

577

578

579

580

581

582

583

584

585

586

587

588

589

590

591

50. Light, B., Perovich, D. K., Webster, M., Polashenski, C., \& Dadic, R. Optical Properties of Melting First-Year Arctic Sea Ice. J. Geophys. Res. Oceans 120, 7657-7675 (2015).

51. Kwok, R. \& Cunningham, G. F. ICESat over Arctic sea ice: Estimation of snow depth and ice thickness. J. Geophys. Res. 113, C08010 (2008).

52. Perovich, D. et al. Observing and understanding climate change: Monitoring the mass balance, motion, and thickness of Arctic sea ice, http://imb-crrel-dartmouth.org (2017).

53. Kwok, R. et al. Airborne surveys of snow depth over Arctic sea ice. J. Geophys. Res. 116, C11018 (2011).

54. Kwok, R., et al. Intercomparison of snow depth retrievals over Arctic sea ice from radar data acquired by Operation IceBridge, Cryosphere, 11, 2571-2593 (2017).

55. Maksym, T., Stammerjohn, S. E., Ackley, S. \& Massom, R. Antarctic sea ice - A polar opposite? Oceanography 25(3), 140-151 (2012).

56. Kwok, R., Pang, S. S. \& Kacimi, S. Sea ice drift in the Southern Ocean: Regional patterns, variability, and trends. Elem. Sci. Anth. 5, 32 (2017).

57. Worby, A. P., Massom, R. A., Allison, I., Lytle, V. I. \& Heil, P. East Antarctic sea ice: A review of its structure, properties, and drift, in Antarctic Sea Ice: Physical Processes, Interactions and Variability, Antarct. Res. Ser. 74, 41-67 (ed. M. O. Jeffries) (AGU, Washington, D. C., 1998).

58. Simmonds, I. \& Keay, K. Mean Southern Hemisphere extratropical cyclone behavior in the 40-year NCEP-NCAR reanalysis. J. Clim. 13, 873-885 (2000).

59. Worby, A. P. et al. Thickness distribution of Antarctic sea ice. J. Geophys. Res. 11, C05S92 (2008). 
592

593

594

595

596

597

598

599

600

601

602

603

604

605

606

607

608

609

610

611

612

613

60. Kurtz, N. T. \& Markus, T. Satellite observations of Antarctic sea ice thickness and volume. J. Geophys. Res. 117, C08025 (2012).

61. Lindsay, R. \& Schweiger, A. Arctic sea ice thickness loss determined using subsurface, aircraft, and satellite observations. Cryosphere 9, 269-283 (2015).

62. Weeks, W. In Sea Ice. (University of Alaska Press, Fairbanks, Alaska, USA, 2010).

63. Arndt, S., et al. Influence of snow depth and surface flooding on light transmission through Antarctic pack ice. J. Geophys. Res. Oceans 122, 2108-2119 (2017).

64. Iacozza, J. \& Barber, D. G. An examination of the distribution of snow on sea-ice. Atmosphere-Ocean. 37, 21-51 (1999).

65. Toyota, T. et al. On the extraordinary snow on the sea ice off East Antarctica in late winter, 2012. Deep Sea Res., Part II 131, 53 -67 (2016).

66. Lecomte, O., Fichefet, T., Flocco, D., Schroeder, D. \& Vancoppenolle, M. Interactions between wind-blown snow redistribution and melt ponds in a coupled ocean-sea ice model. Ocean Modelling 87, 67-80 (2015).

67. Arndt, S., Willmes, S., Dierking, W. \& Nicolaus, M. Timing and regional patterns of snowmelt on Antarctic sea ice from passive microwave satellite observations. J. Geophys. Res. Oceans 121, 5916-5930 (2016).

68. Massom, R. A., Lytle, V. I., Worby, A. P. \& Allison, I. Winter snow cover variability on East Antarctic sea ice. J. Geophys. Res. 103, 24, 837-24,855 (1998).

69. Maksym, T. \& Markus, T. Antarctic sea ice thickness and snow-to-ice conversion from atmospheric reanalysis and passive microwave snow depth. J. Geophys. Res. 113, C02S12 (2008). 
614 70. Toyota, T., Massom, R., Tateyama, K., Tamura, T. \& Fraser, A. Properties of snow overlying 615 the sea ice off East Antarctica in late winter, 2007. Deep-Sea Res. II 58(9-10), 1137-1148 $616 \quad(2011)$.

617 71. Lubin, D. \& Massom, R. A. Polar Remote Sensing Volume 1: Atmosphere and Ocean, 618 (Springer, Chichester, U. K., 2006).

619 72. Kwok, R. \& Maksym, T. Snow depth of the Weddell and Bellingshausen sea ice covers from 620 IceBridge surveys in 2010 and 2011: An examination. J. Geophys. Res. Oceans 119, $62141414167(2014)$.

622 73. Flato, G. et al. Evaluation of Climate Models. In: Climate Change 2013: The Physical 623 Science Basis. Contribution of Working Group I to the Fifth Assessment Report of the 624 Intergovernmental Panel on Climate Change (eds. Stocker, T. F. et al.) (Cambridge 625 University Press, Cambridge, United Kingdom and New York, NY, USA, 2013).

626 74. Hunke, E., Lipscomb, W. \& Turner, A. Sea-ice models for climate study: Retrospective and 627 new directions. J. Glacio. 56(200), 1162-1172 (2010).

628 75. Sturm, M., Holmgren, J., Koenig, M. \& Morris, K. The thermal conductivity of seasonal 629 snow. J. Glaciol. 43, 26-41 (1997).

630 76. Blazey, B. A., Holland, M. M. \& Hunke, E. C. Arctic Ocean sea ice snow depth evaluation 631 and bias sensitivity in CCSM. Cryosphere 7, 1887-1900 (2013).

632 77. Lecomte, O. et al. On the formulation of snow thermal conductivity in large-scale sea ice 633 models. J. Adv. Model. Earth Syst. 5, 542-557 (2013).

634 78. Castro-Morales, K. et al. Sensitivity of simulated Arctic sea ice to realistic ice thickness 635 distributions and snow parameterizations. J. Geophys. Res. Oceans 119, 559-571 (2014). 
636

637

638

639

640

641

642

643

644

645

646

647

648

649

650

651

652

653

654

655

656

657

79. Yang, D. et al. Accuracy of Tretyakov Precipitation Gauge: Result of WMO Intercomparison. Hydrol. Proc. 9, 877-895 (1995).

80. Dai, A. Precipitation characteristics in eighteen coupled climate models. J. Clim. 19, 46054630 (2006).

81. Ricker, R., Hendricks, S., Perovich, D. K., Helm, V. \& Gerdes, R. Impact of snow accumulation on CryoSat- 2 range retrievals over Arctic sea ice: An observational approach with buoy data. Geophys. Res. Lett. 42, 4447-4455 (2015).

82. Nandan, V. et al. Effect of snow salinity on CryoSat-2 Arctic first-year sea ice freeboard measurements. Geophys. Res. Lett. 44(10), 419-10, 426 (2017).

83. Goosse, H. et al. Quantifying climate feedbacks in polar regions. Nature Communications, 9, 1919 (2018).

84. Massonnet, F. et al. Arctic sea-ice change tied to its mean state through thermodynamic processes. Nature Climate Change 8, 599-603 (2018). .

85. Jordan, R., Albert, M. \& Brun, E. Physical processes within the snow cover and their parameterization, in "Snow and Climate: Physical Processes, Surface Energy Exchange and Modeling”, by Armstrong, R. L. and Brun, E., Cambridge University Press, 12-69 (2008).

86. Liston, G. E. et al. Distributed Snow Evolution Model for Sea Ice Applications (SnowModel). J. Geophys. Res. Oceans (2018).

87. Giles, K. A., et al. Combined airborne laser and radar altimeter measurements over the Fram Strait in May 2002. Remote Sens. Environ. 111, 182 - 194 (2007).

88. Koenig, L., Martin, S., Studinger, M. \& Sonntag, J. Polar airborne observations fill gap in satellite data. Eos 91(38), 333-334 (2010). 
658

659

660

661

662

663

664

665

666

667

668

669

670

671

672

673

674

675

676

677

678

679

680

89. Kurtz, N. \& Farrell, S. Large-scale surveys of snow depth on Arctic sea ice from Operation IceBridge. Geophys. Res. Lett. 38, L20505 (2011).

90. Markus, T. \& Cavalieri, D. J. Snow depth distribution over sea ice in the Southern Ocean from satellite passive microwave data. Antarct. Res. Ser. 74, 19-39 (ed. M. O. Jeffries) (AGU, Washington, D. C., 1998).

91. Comiso, J. C., Cavalieri, D. J. \& Markus, T. Sea ice concentration, ice temperature, and snow depth using AMSR-E data. IEEE Trans. Geosci. Remote Sens. 41(2), 243-252 (2003).

92. Stroeve, J. C. et al. Impact of surface roughness on AMSR-E sea ice products. IEEE Trans. Geosci. Remote Sens. 44, 3103-3117 (2006).

93. Worby, A. P., Markus, T., Steer, A. D., Lytle, V. I. \& Massom, R. A. Evaluation of AMSR-E snow depth product over East Antarctic sea ice using in situ measurements and aerial photography. J. Geophys. Res. 113, C05S94 (2008).

94. Brucker, L. \& Markus, T. Arctic-scale assessment of satellite passive microwave-derived snow depth on sea ice using Operation IceBridge airborne data. J. Geophys. Res. Oceans 118, 2892-2905 (2013).

95. Willmes, S., Nicolaus, M. and Haas, C. The microwave emissivity variability of snow covered first-year sea ice from late winter to early summer: A model study. Cryosphere 8(3), 891-904 (2014).

96. Guerreiro, K., Fleury, S., Zakharova, E., Remy, F. \& Kourev, A. Potential for estimation of snow depth on Arctic sea ice from CryoSat2 and SARAL/AltiKa missions. Remote Sens. Environ. 186, 339-349 (2016).

97. Kwok, R. \& Markus, T. Potential basin-scale estimates of Arctic snow depth with sea ice freeboards from CryoSat-2 and ICESat-2: An exploratory analysis. Adv. Space Res. (2017). 
681 98. Holland, M. \& Perovich, D. Sea Ice Summer Camp: Bringing Together Sea Ice Modelers and 682 Observers to Advance Polar Science. Bull. Am. Meteorol. Soc. 98(10), 2057-2059 (2017).

683 99. Jackson, K., Wilkinson, J., Maksym, T., Meldrum, D., Beckers, J., Haas, C. \& Mackenzie, D. 684 A novel and low-cost sea ice mass balance buoy. J. Atmos. Ocean Technol. 30(11), 2676$6852688(2013)$.

686 100. Nicolaus, M. et al. Snow height and air temperature on sea ice from Snow Buoy 687 measurements. Alfred Wegener Institute, Helmholtz Center for Polar and Marine Research, 688 Bremerhaven, doi:10.1594/PANGAEA.875638 (2017).

689

690

691 Figure Captions:

692 Copy here and re-order references

693

694

695

696 Text Box:

697 Copy here and re-order references 